\title{
A 3D hydrodynamic-biogeochemical model for assessing artificial oxygenation in a riverine salt-wedge estuary
}

\author{
M.R. Hipsey ${ }^{\text {a }}$, L.C. Bruce ${ }^{a}$ and K. Kilminster ${ }^{\text {b }}$ \\ ${ }^{a}$ School of Earth and Environment, The University of Western Australia, Crawley WA 6009, Australia. \\ Email:matt.hipsey@uwa.edu.au \\ ${ }^{b}$ Water Science Branch, Department of Water, Perth WA 6842, Australia.
}

\begin{abstract}
The presence of anoxia and hypoxia in bottom waters is regularly observed in salt wedge riverine estuaries. The extent of oxygen depletion depends both on physical circulation patterns and biogeochemical processes such as organic matter mineralization, photosynthesis and sediment oxygen demand. Over the past decade, reduced flows in the Swan-Avon River catchments have led to reduced flushing of nutrients and organic matter in the Swan-Canning estuarine system in Western Australia (WA), and more intense stratification that has been able to penetrate further upstream. As a result, hypoxia and anoxia in the upper reaches is a now a persistent management challenge due to detrimental effects on estuarine biodiversity and overall amenity and health of the river. As part of a multi-pronged strategy to tackle the problem of eutrophication in the estuary, several oxygenation plants have been installed in the
\end{abstract} upper reaches of the river that use micro-diffusers to re-oxygenate anoxic and hypoxic waters.

In this study we have aimed to simulate oxygen dynamics and assess the overall efficiency of the oxygenation plants through development of a finite volume coupled hydrodynamic - biogeochemical model of the Upper Swan estuary (Figure 1). The model accurately captured the saltwedge dynamics and extent and severity of hypoxia and anoxia. The model has been used to explore budgets of oxygen and nutrients for different plant operational regimes, and has allowed us to define the spatiotemporal benefit of these scenarios. The results are used to inform the most cost effective way to achieve the desired improvements in river habitat.

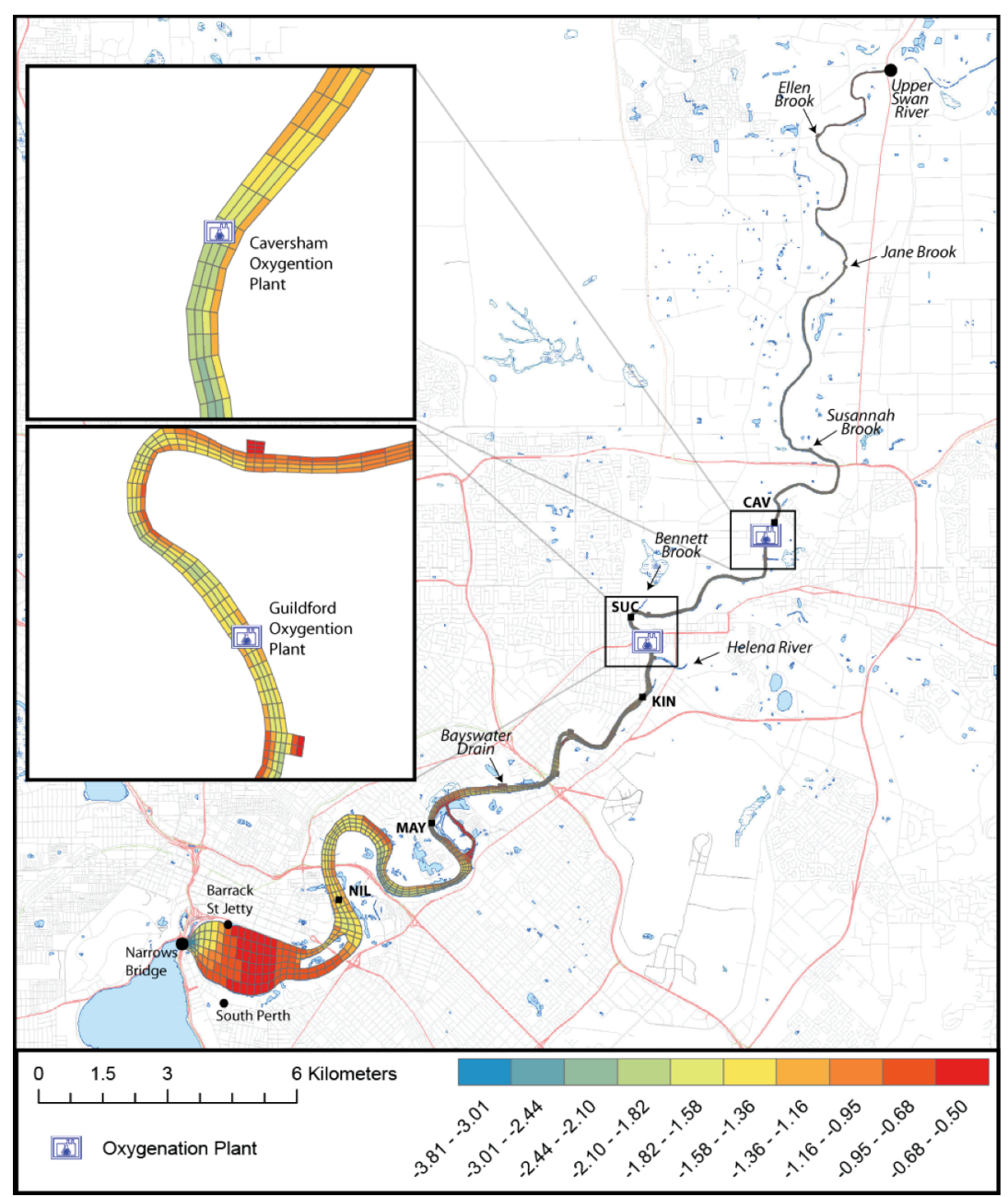

Figure 1. Upper Swan estuary computational mesh from Narrows Bridge the to Gt Northern Hwy Bridge, with two zoom regions shown near the Guildford and Caversham oxygenation plants, river inflow locations, and validation points. Colour scale indicates depth (mAHD). 


\section{INTRODUCTION}

The presence of anoxia and hypoxia in bottom waters is regularly observed in salt-wedge riverine estuaries (e.g., Paerl and Pinckney 1998; Roberts et al. 2013). The balance of inputs of tidally driven salt water input and freshwater river inflows sets up a salt-wedge stratification pattern that prevents mixing between oxygen deplete bottom waters and the atmosphere. The extent and severity of oxygen depletion depends both on physical circulation patterns and biogeochemical processes such as organic matter mineralization, photosynthesis and sediment oxygen demand.

Hypoxia and anoxia in the upper reaches of the Swan-Canning estuary (WA) is a now a persistent management challenge, with detrimental effects on estuarine biodiversity and the overall amenity and health of the river. This is largely a result of reduced flows in the surrounding Swan-Avon River catchments that have led to reduced flushing of nutrients and organic matter as well as changes in the stratification patterns observed within the estuary (Kurup and Hamilton 2002). In addition, land-use changes within the catchment have increased organic loading to the estuary (Petrone et al. 2009). As part of a strategy to tackle the problem of oxygen depletion, artificial oxygenation of the stratified upper river reaches has been a remediation strategy for poor water quality within the Canning River for more than 16 years, and in the upper Swan River for the past 6 years. There are currently two oxygenation plants on each of the Swan and Canning rivers. These oxygenation plants pump oxygen-depleted water from near the riverbed, supersaturate it with oxygen, and return the newly oxygenated water to the bottom waters of the estuary through several micro-diffusers.

Data from weekly monitoring of water quality and intensive operational trials around the plants has indicated obvious improvements in oxygen status due to artificial oxygenation. However, the horizontal dispersion and overall persistence of the oxygenated water can vary significantly depending on environmental conditions such as the wind, tide and riverine inflows. It is desirable to better understand how oxygenation plant efficiency varies under a range of environmental conditions, the extent to which they improve water quality, and how this would differ under different operational strategies. Given the oxygenation plants are energy intensive to operate, a simulation model able to quantify conditions where oxygenation is more or less effective also opens up the opportunity to conduct a cost-benefit analysis.

This paper therefore reports the development and validation of a high-resolution coupled hydrodynamicbiogeochemical model of the Upper Swan estuary for the purposes of assessing oxygen dynamics. The model simulates the interactions between physical and biogeochemical processes that govern estuarine response to oxygenation, and in particular to quantify the pathways of oxygen, nutrients and organic matter. The model is used to conduct a cost-benefit analysis of hypothetical oxygenation plant operational regimes, by introducing a method for assessing how estuarine habitat is improved by oxygenation at the estuary system-scale.

\section{MODEL APPROACH \& SETUP}

TUFLOW-FV was applied for this investigation, which is a 3D flexible-mesh (finite volume) hydrodynamic model (BMTWBM, 2013). The model accounts for variations in water level, the horizontal salinity distribution and vertical density stratification in response to inflows, salt-wedge dynamics and surface thermodynamics. The finite volume numerical scheme solves the conservative integral form of the non linear shallow water equations in addition to the advection and transport of scalar constituents such as salinity and temperature and the state variables from the coupled biogeochemical model. The equations are solved in 3D with baroclinic coupling with both salinity and temperature using the UNESCO equation of state (Fofonoff and Millard 1983). Both $1^{\text {st }}$ and $2^{\text {nd }}$ order spatial integration schemes are available, and the temporal integration scheme is explicit and uses both mode-splitting and dynamically varying timesteps to maximize computational efficiency subject to Courant and Peclet stability constraints. Surface momentum exchange and heat dynamics are solved internally within the model from available meteorological boundary condition data. In the current application, turbulent mixing of momentum and scalars has been calculated using the Smagorinsky scheme in a horizontal plane and through coupling with the General Ocean Turbulence Model (GOTM, Umlauf and Burchard 2003) for vertical mixing.

The mesh (in plan view), consists of triangular and quadrilateral elements of different size spanning a domain from the Narrows Bridge to the Great Northern Hwy bridge. The mesh is loosely based on a curvilinear designed grid, with custom elements around complex areas (Figure 1). The channel has approximately 4-8 elements across the river below Caversham, with 1 cell across from the region upstream of Caversham to the Avon River upstream boundary point (S616076 flow gauging station). The depths on the grid were interpolated from recently collected bathymetric data available from the WA Department of Transport from the Narrows to Caversham, and upstream of this raw depth sounder data collected from the centre of the channel was interpolated and joined to the high-resolution data set. 
The domain is forced by inflows, meteorological and tidal information. At the downstream boundary, data supplied from Barrack St Jetty (water level) \& Narrows Bridge (water quality). Inflows (with available water quality data interpolated to daily resolution) are input at: Swan River, Ellen Brook, Jane Brook, Susannah Brook, Helena River, Bennett Brook, Bayswater Drain. Meteorological data for the model is from the South Perth BoM station, and included of solar radiation, wind, air temperature, humidity, rain and cloud cover.

The hydrodynamic model was coupled with the Framework for Aquatic Biogeochemical Models (FABM), which is a relatively new open-source code base that links aquatic models simulation of aquatic biogeochemical and ecological dynamics (fabm.sourceforge.net). In this study, the Aquatic Ecodynamic (AED) modules that are linked to FABM are used and they allow simulation of the C, N, P, O, and Si cycles including inorganic nutrient, organic matter, phytoplankton and zooplankton components. Since the focus of this study was on oxygen, the AED configuration was simplified to a single bulk chlorophyll-a group and no zooplankton. The simulated state variables for this configuration are summarised in Table 1, showing those subject to mixing, transport and boundary forcing by the hydrodynamic driver, along with derived variables (eg. TN, TP, CT, EC). For brevity, this paper highlights the oxygen (DO) predictions.

One of the key drivers for estuarine deoxygenation is the sediment oxygen demand. A study to develop a sediment biogeochemical model (Norlem et al. 2013) was used to simulate the highresolution dynamics of surficial sediment under various conditions, including the highly dynamic conditions as created by the diel changes in redox conditions created by periodic oxygenation. The results from this high-resolution model were used to develop a simpler sediment oxygen demand, $F_{S O D}$, equation:

$$
F_{S O D_{e}}=F_{S O D_{20}}\left[\frac{D O_{e}}{D O_{e}+K_{D O}}\right] \vartheta_{S O D}{ }^{T_{e}-20}
$$

where $e$ refers to specific conditions in each model element. This was used within the 3D model domain allowing us to capture the essential dynamics relevant to the environmental conditions experienced here without the overhead of the detailed sediment diagenesis model.
Table 1. Simulated variables in the model.

\begin{tabular}{|c|c|c|}
\hline Variable & Units & Common Name \\
\hline $\mathbf{T}$ & ${ }^{\circ} \mathrm{C}$ & Temperature \\
\hline $\mathbf{S}$ & psu & Salinity \\
\hline $\mathrm{EC}$ & $\mathrm{uS} \mathrm{cm} \mathrm{cm}^{-1}$ & Electrical conductivity \\
\hline I & $\mathrm{mE} \mathrm{m} \mathrm{m}^{-2} \mathrm{~s}^{-1}$ & Shortwave light intensity \\
\hline$\eta_{\text {PAR }}$ & $\mathrm{m}^{-1}$ & PAR extinction coefficient \\
\hline $\mathbf{S S}_{1}$ & $\mathrm{~g} \mathrm{~m}^{-3}$ & Inorganic suspended solids - small \\
\hline $\mathbf{S S}_{2}$ & $\mathrm{~g} \mathrm{~m}^{-3}$ & Inorganic suspended solids - large \\
\hline $\mathrm{CT}$ & NTU & Turbidity \\
\hline DO & $\mathrm{g} \mathrm{DO} \mathrm{m}^{-3}$ & Dissolved oxygen \\
\hline DOC & $\mathrm{g} \mathrm{C} \mathrm{m}^{-3}$ & Dissolved organic carbon \\
\hline POC & $\mathrm{g} \mathrm{C} \mathrm{m}^{-3}$ & Particulate organic carbon \\
\hline FRP & $\mathrm{g} \mathrm{P} \mathrm{m}^{-3}$ & Filterable reactive phosphorus \\
\hline DOP & $\mathrm{g} \mathrm{P} \mathrm{m}^{-3}$ & Dissolved organic phosphorus \\
\hline POP & $\mathrm{g} \mathrm{P} \mathrm{m}^{-3}$ & Particulate organic phosphorus \\
\hline PIP & $\mathrm{g} \mathrm{P} \mathrm{m}^{-3}$ & Particulate inorganic phosphorus \\
\hline $\mathrm{TP}$ & $\mathrm{g} \mathrm{P} \mathrm{m}^{-3}$ & Total Phosphorus \\
\hline $\mathbf{N H}_{4}^{+}$ & $\mathrm{g} \mathrm{N} \mathrm{m}^{-3}$ & Ammonium \\
\hline $\mathrm{NO}_{3}^{-}$ & $\mathrm{g} \mathrm{N} \mathrm{m}^{-3}$ & Nitrate \\
\hline DON & $\mathrm{g} \mathrm{N} \mathrm{m}^{-3}$ & Dissolved organic nitrogen \\
\hline PON & $\mathrm{g} \mathrm{N} \mathrm{m}^{-3}$ & Particulate organic nitrogen \\
\hline $\mathrm{TN}$ & $\mathrm{g} \mathrm{N} \mathrm{m}^{-3}$ & Total Nitrogen \\
\hline RSi & $\mathrm{g} \mathrm{Si} \mathrm{m}^{-3}$ & Reactive Silica \\
\hline Chla & $\mathrm{mmol} \mathrm{C} \mathrm{m}^{-3}$ & Chlorophyll-a \\
\hline
\end{tabular}

\section{MODEL VALIDATION}

A substantial amount of data from all available monitoring stations (20 long-term plus 38 ad hoc sites for the Upper Swan) was processed for the purposes of validating and testing the model against the observed estuarine dynamics and the effect of the oxygenation plants. The model was run for the 2008 and 2010 calendar years and compared against salinity, temperature, oxygen and nutrient patterns. In particular this paper summarises the salt wedge propagation and extent of hypoxia and anoxia.

\subsection{Salinity}

Comparison of the modelled and observed surface and bottom salinity is shown in Figure 2 for 2008 (left). In general terms the salt-wedge is very well predicted, with the model accurately capturing the horizontal variation in salinity in addition to the differences between the surface and bottom waters during small and large flow events. The model uses the same parameters and grid for both the 2008 (wet) and 2010 (dry) simulations, and confidently predicts the dynamics in both years (2010 not shown). The $\mathrm{R}^{2}$ values vary between $0.85-0.95$, with Nash-Sutcliffe efficiency parameters of $\sim 0.95$ indicating a very high level of agreement.

\subsection{Oxygen}

Time-series comparisons of oxygen concentrations for 2008 (Figure 2) and 2010 (not shown) show significant variability. In 2008 the moderate autumn flows creates long periods of anoxia which is then 
replaced by well mixed conditions in winter. In 2010 the lower flows all year create a different pattern, which is also complicated by periodic operation of the Guildford oxygenation plant. Overall the model predictions capture the seasonal changes well and the changes in both the surface and bottom waters (Figure 3). Higher $\mathrm{R}^{2}$ values were recorded in 2008 due to the larger month-to-month

variability in 2010 making the point comparisons less effective. Overall the model has an average error of $20-25 \%$, which is considered to be very high level of model performance for biogeochemical variables in estuarine systems (e.g., refer to Ahronditsis and Brett, 2004).

A detailed comparison of the model with data collected in 2010 at high resolution from around the Guildford oxygenation plant was also able to
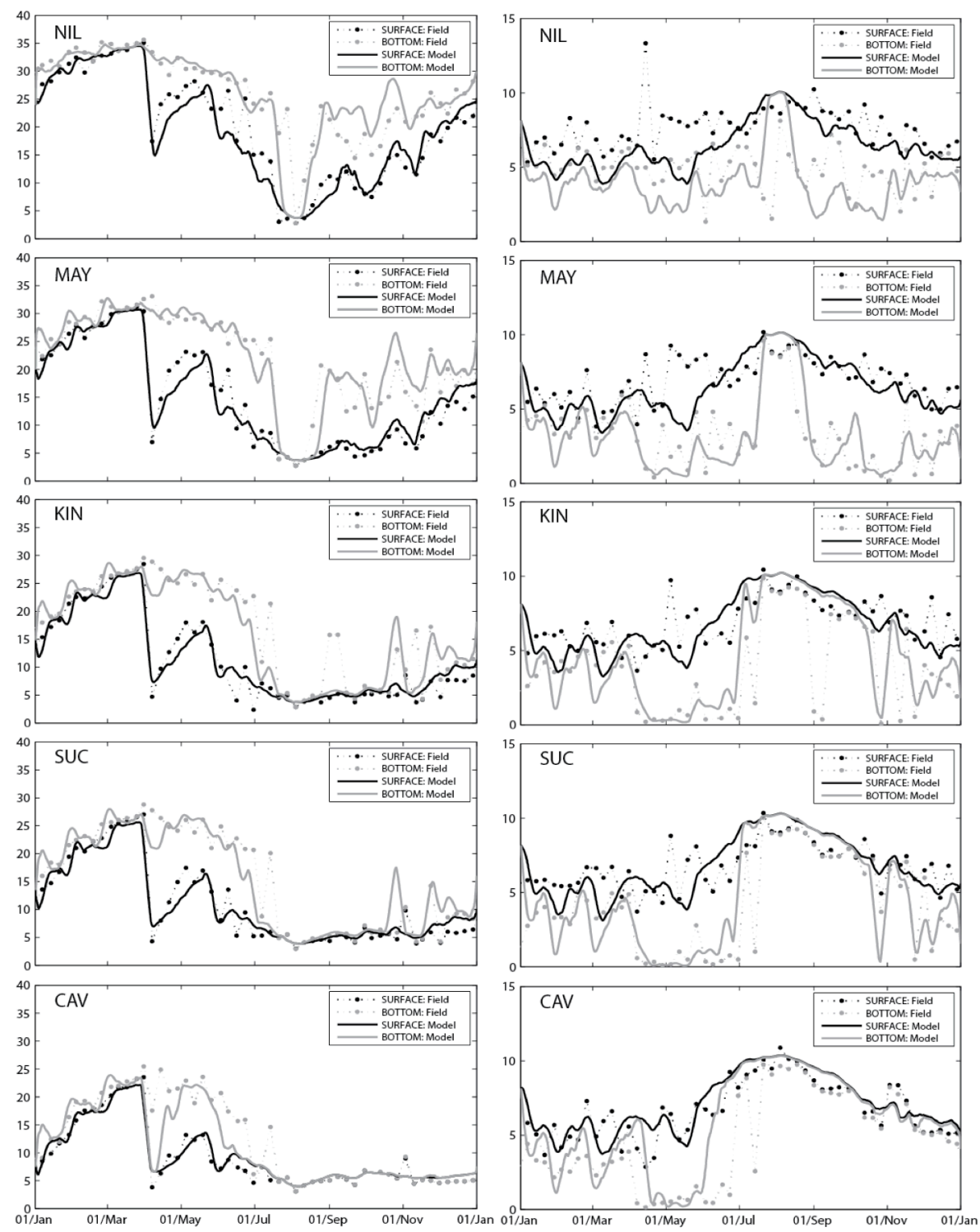

Figure 2. Upper Swan estuary salinity (psu; left) and dissolved oxygen concentration ( $\mathrm{g} \mathrm{O}_{2} \mathrm{~m}^{-3}$; right) for the year 2008 comparing simulated and observed values at 5 monitoring sites along the estuary length.
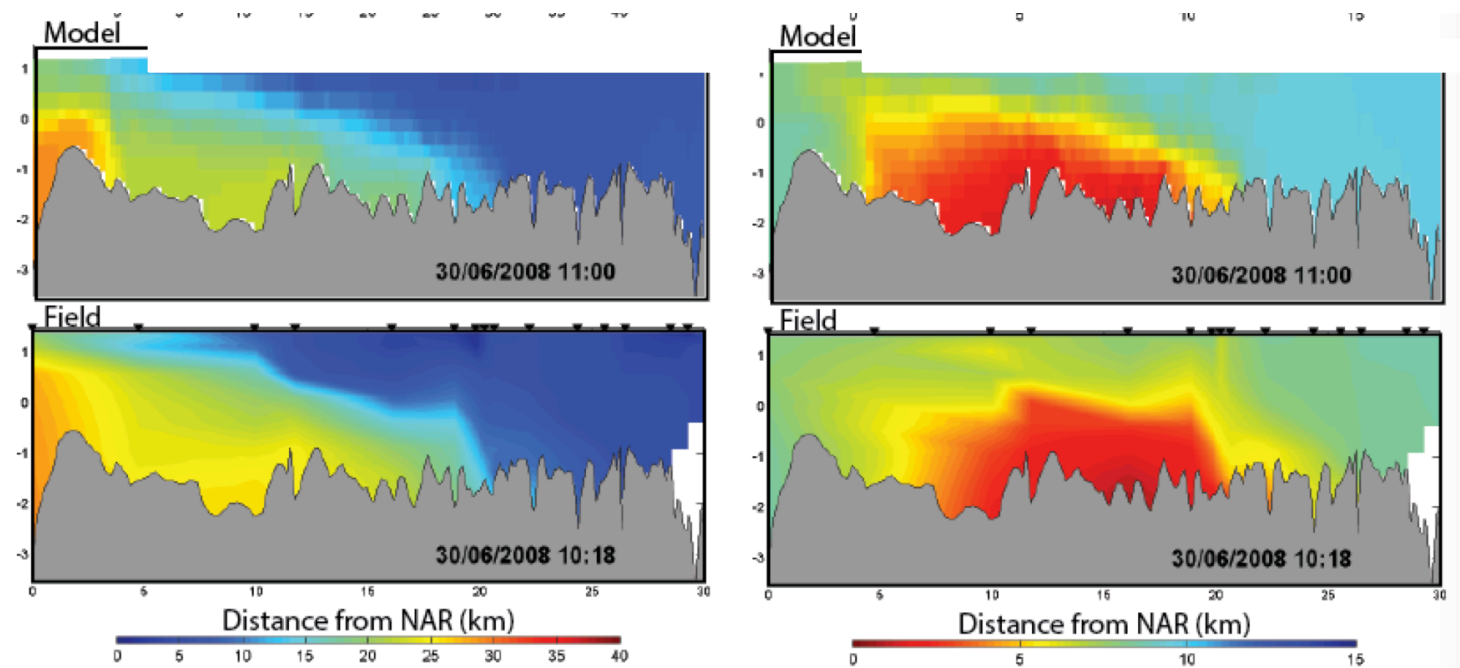

Figure 3. Cross-section ('curtain') plots comparing modelled and field salinity (psu; left) and oxygen ( $\mathrm{mg} \mathrm{O}_{2} \mathrm{~L}^{-1}$; right) for June 2008. The field plots are based on a contouring around 20 profile data locations. 
demonstrate the model was able to simulate the rise and dispersion of the oxygenation plume, though poor resolution of the forcing meteorological data in this region, meant that some discrepancies emerged in the model results during some of the comparisons with the high-resolution profile data (not shown). Figure 4 is a system scale validation of the spatial extent of hypoxia and anoxia across the estuary.

\section{OXYGENATION SCENARIOS}

A range of hypothetical scenarios were explored to assess how sensitive the river oxygen would be to alternate oxygenation operational scenarios. These were chosen in consultation with relevant stakeholders and are presented as an initial set of "what-if" scenarios to provide a broad indication of how the river responds to oxygenation under different flow regimes. The scenarios tested are listed in Table 2 and range from sOXY0 -
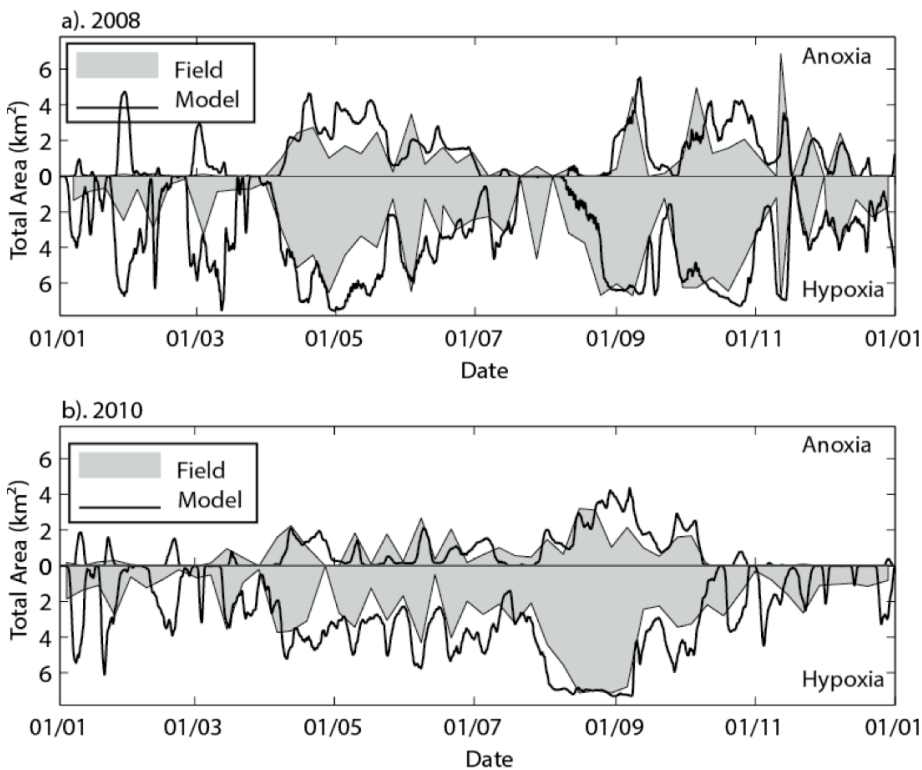

Figure 4. The total area of anoxia $\left(<2 \mathrm{mg} \mathrm{O}_{2} \mathrm{~L}^{-1}\right)$ and hypoxia $\left(<4 \mathrm{mg} \mathrm{O}_{2} \mathrm{~L}^{-1}\right)$ within the estuary for: a) 2008 and b) 2010 , comparing the model (black line) and spatially interpolated weekly profile data (shaded region).

- $\quad$ The amount of oxygen input: $\boldsymbol{B} \boldsymbol{A S E}=30 \mathrm{~kg} \mathrm{hr}^{-1} ; \boldsymbol{H I G H}=60 \mathrm{~kg} \mathrm{hr}^{-1}$;

- The timing of oxygenation input: in particular, whether it is input at night time (during hours of cheaper electricity prices), or whether it is input on certain phases of the tidal cycle:

Constant $=24 \mathrm{hr}$ /day constant input of oxygen from the oxygenation plant;

Economic $=$ Night-time input only $(8 \mathrm{pm}-8 \mathrm{am})$, with zero during the day;

Flood/Ebb tide = Analysis of tidal level at Narrows Bridge to only put in oxygenation water when on a flood or ebb portion of tidal cycle.

- $\quad$ The location of input: whether it is input at Guildford, Caversham, or both (refer to Figure 1).

Table 2. Summary of scenarios run to assess the impact of the Guildford \& Caversham oxygenation plants.

\begin{tabular}{|c|c|c|c|}
\hline $\begin{array}{l}\text { Scenario } \\
\text { Name }\end{array}$ & Flow condition & Guildford plant operational regime & Caversham plant operational regime \\
\hline sOXY0 & 2010 - low flow year & No oxygenation & No oxygenation \\
\hline sOXYV & 2010 - low flow year & $\begin{array}{c}\text { Actual input rate and regime of oxygen } \\
\text { during } 2010\end{array}$ & nation \\
\hline sOXY1 & 2010 - low flow year & $\begin{array}{l}\text { Constant oxygen plant input at the "BASE" } \\
\text { input rate }\end{array}$ & $\begin{array}{l}\text { Constant oxygen plant input at the } \\
\text { "BASE" input rate }\end{array}$ \\
\hline sOXY4 & 2010 - low flow year & No oxygenation & $\begin{array}{l}\text { Constant oxygen plant input at the } \\
\text { "HIGH" input rate }\end{array}$ \\
\hline sOXY5 & 2010 - low flow year & $\begin{array}{l}\text { Economic timing of inputs at the "HIGH" } \\
\text { input rate }\end{array}$ & $\begin{array}{l}\text { Economic timing of inputs at the "HIGH" } \\
\text { input rate }\end{array}$ \\
\hline sOXY6 & 2010 - low flow year & $\begin{array}{l}\text { Economic timing of inputs at the "BASE" } \\
\text { input rate }\end{array}$ & $\begin{array}{l}\text { Economic timing of inputs at the "BASE" } \\
\text { input rate }\end{array}$ \\
\hline sOXY7 & 2010 - low flow year & $\begin{array}{c}\text { Flood-tide timing of inputs at the "BASE" } \\
\text { input rate }\end{array}$ & $\begin{array}{l}\text { Ebb-tide timing of inputs at the "BASE" } \\
\text { input rate }\end{array}$ \\
\hline
\end{tabular}

The scenario results of bottom water oxygen predictions highlight the extent of the improvement the plants have both downstream to KIN and upstream past MSB. Substantial increases of the order of $100-200 \%$ are predicted in the region of around $10 \mathrm{~km}$ from the plant input point. An oxygenation plant tracer input variable demonstrated the extent of influence being $>30 \mathrm{~km}$ (to $5 \%$ of input concentration).

The effect is more clearly summarised in Figure 5, which demonstrates the relative frequency (y-axis) vs position (x-axis) of benthic area that has been "saved" from anoxia or hypoxia $\left(<4 \mathrm{mgL}^{-1}\right)$ by the oxygenation intervention. Across the different oxygenation scenarios, with both plants running, the area of benthos saved 
could range from 0.6 $1.2 \mathrm{~km}^{2}$ on any given day when the plant was running depending on the plant operation method.

The scenarios have an estimated operating cost ranging from $\$ 200,000-400,000$ per annum, calculated based on a) the timing of oxygen input and typical peak an d offpeak electricity costs, and b) oxygen input costs $\quad(\$ / \mathrm{kg}) . \quad$ By calculating the systemwide annual average of benthic area saved, these scenarios demonstrate a different amount of benefit that is not always proportional to oxygen loading or cost (Figure 6). The results provide a simple summary from the
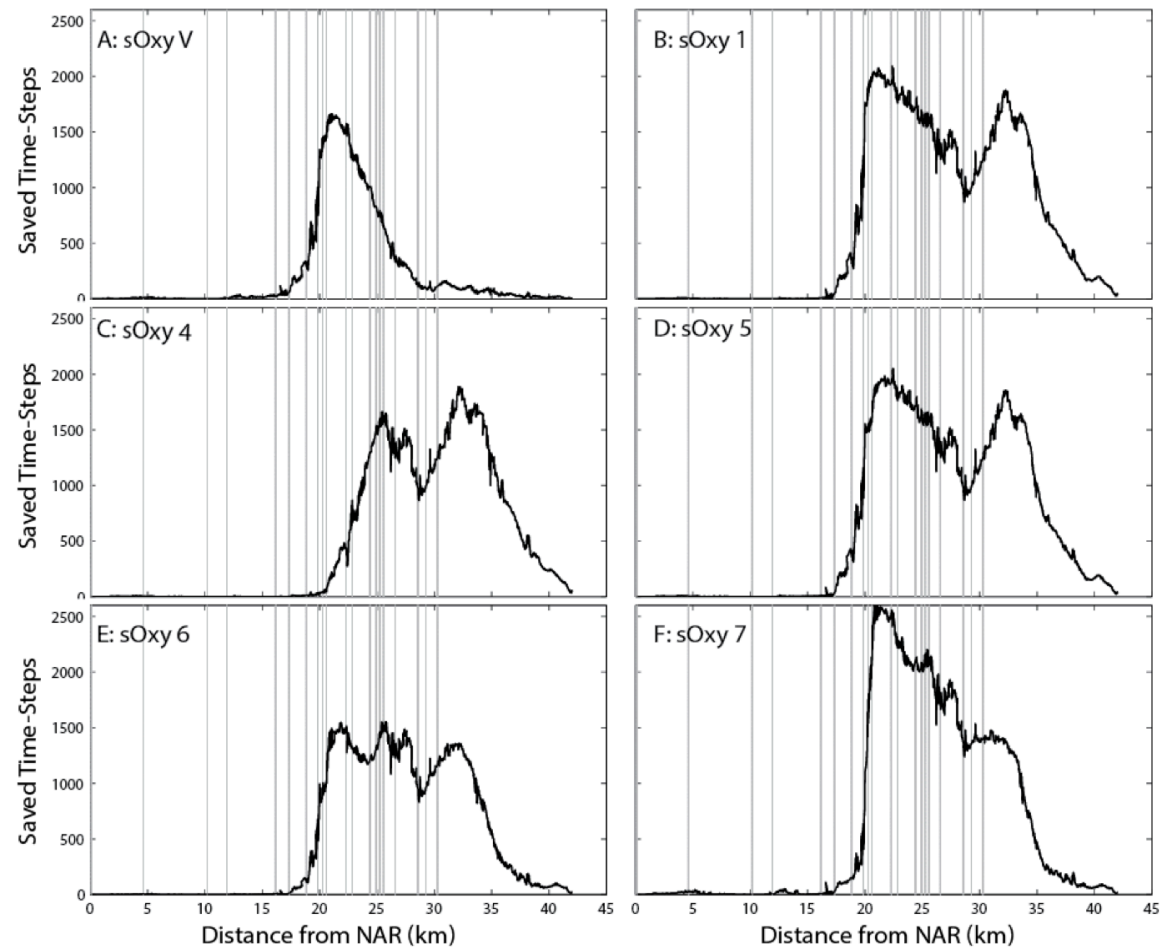

Figure 5. Along-stream transect of "benthic area saved from anoxia and hypoxia" for each scenario. Calculated by summing the area of each cell along the estuary for each time-step where the DO was $>4 \mathrm{mgL}^{-1}$ relative to no oxygenation base case simulation for the same location and at the same time (sOXY0). Grey vertical lines refer to the monitoring stations along the estuary for reference.

more complex model

outlining the annual average benthic area saved relative to oxygen input and expense, and highlights how to optimise environmental benefit for the least cost.

\section{DISCUSSION AND CONCLUSIONS}

The project has served to integrate historical data through development of 3D finite volume model in order to better understand the effectiveness and dynamics of the oxygenation plants within the Swan River estuary. Whilst oxygenation of stratified lakes is relatively common, to date there are no proven examples of models used to simulate the dynamics of artificial oxygenation in a riverine estuary. This work has therefore invested a significant amount of effort into model setup and careful validation. In particular, a substantial amount of data from all available monitoring stations was processed for the purposes of testing the model of which only a small amount is presented in this paper. One of the key drivers for estuarine deoxygenation is the sediment
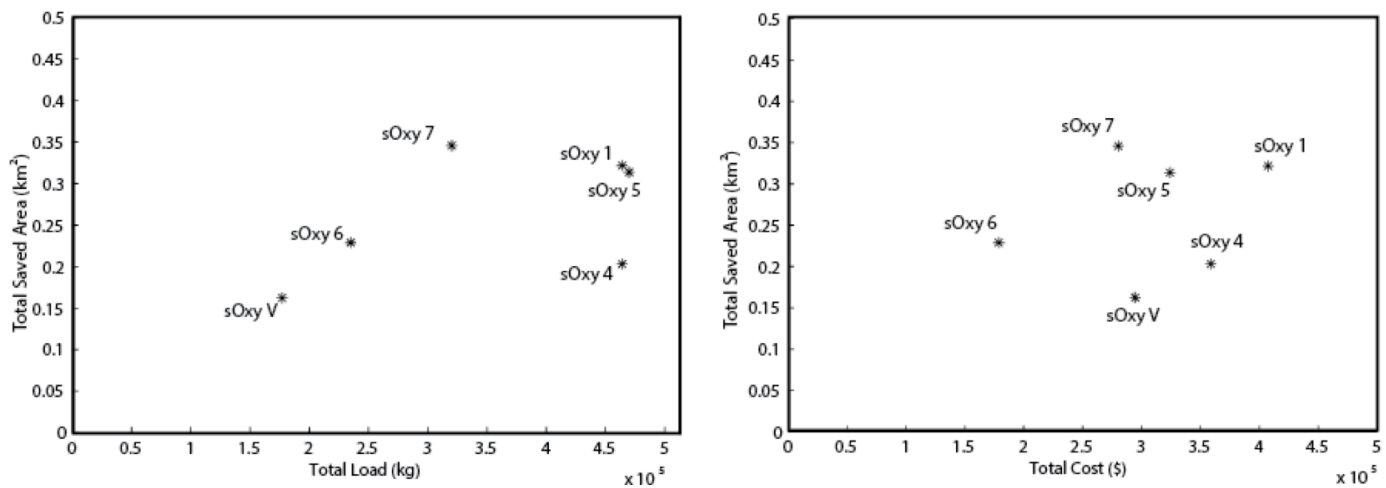

Figure 6. Daily average area of benthos (river bed) saved over a year in the Upper Swan from critically low oxygen concentrations as a function of oxygenation plant input load (left) and total cost (right). Several scenarios shown comparing oxygen input regime and amount (refer to Table 2). Based on low flow conditions. 
Hipsey et al., A 3D finite volume model to assess artificial oxygenation in the Upper Swan estuary

oxygen demand. This model uses a simple reduced model from a detailed sediment biogeochemical model that was setup and used to simulate the high-resolution dynamics of chemistry of sediment subjected to periodic oxygenation.

Overall, the model demonstrated it was able to confidently predict the salt-wedge dynamics, both at the estuary scale, and at the focus area surrounding Guildford and Caversham. The river is particularly curved in this region and hydrodynamic models typically find it difficult to resolve the sharp thermocline in this environment, so the accurate hydrodynamic simulations presented here, both during normal flow conditions (2008) and very low flow conditions (2010), provides confidence the model is suitable for this environment and fit for purpose. Nutrients were additionally simulated but have not been the focus of this paper, and further work is required to improve the nutrient validation so the effect of artificial oxygenation on nutrient retention in the water and sediment can be further assessed.

The model is applied to explore various oxygenation scenarios with performance of the intervention assessed using several metrics, including extent of influence, degree of reoxygenation of the bottom water, and the amount of benthic area "saved" from experiencing hypoxic or anoxic conditions. The results highlighted the ability of the infused oxygen to significantly improve oxygen conditions over an extent of $20-40 \mathrm{~km}$, depending on the rate of input and flow conditions. In general, adding more oxygen would improve the oxygen conditions to a greater extent, however this would also enhance the area of the water column that is reaching saturated and therefore the benefit is not linearly related to input. Potential for optimisation of the input regime was also demonstrated, such as the through changing timing of oxygen input (e.g. night time or aligned with tidal cycles), which could lead to some differences in plant effectiveness. This information can be used to support cost-benefit analyses such as presented in Figure 6. The scenarios presented here are under low flow conditions (equivalent to 2010 flow conditions), and further work assessing optimal plant performance under different flow conditions is being undertaken. Future work will explore the potential benefit of operating the plants under local "DO control", whereby plant inputs are guided by real-time data from in situ sensors.

\section{ACKNOWLEDGMENTS}

We acknowledge the Swan River Trust for supporting the model development and thank Dr Kerry Trayler for her input. We also acknowledge the technical support from B. Busch from UWA, and M. Robb, S. Larsen, Z. Goss, and G. Evans from the WA Department of Water. We also thank I. Teakle from BMTWBM for advice.

\section{REFERENCES}

Arhonditsis, G., and Brett, M. (2004). Evaluation of the current state of mechanistic aquatic biogeochemical modeling. Marine Ecology Progress Series, 271, 13-26.

BMTWBM (2013). TUFLOW FV Science Manual. Available from: http://www.tuflow.com/Download/TUFLOW_FV/Manual/FV_Science_Manual_2013.pdf

Fofonoff, N., and Millard, R. (1983). Algorithms for computation of fundamental properties of seawater. UNESCO technical papers in marine science.

Kurup, R.G. and Hamilton, D.P. (2002). Flushing of dense, hypoxic water from a cavity of the Swan River estuary, Western Australia. Estuaries, 25, 908-915.

Norlem, M., Paraska, D. and Hipsey, M.R. (2013). Sediment-water oxygen and nutrient fluxes in a hypoxic estuary. MODSIM2013 - 20th International Congress on Modelling and Simulation, Adelaide, Australia. Modelling and Simulation Society of Australia and New Zealand, December 2013.

Paerl, H., and Pinckney, J. (1998). Ecosystem responses to internal and watershed organic matter loading: consequences for hypoxia in the eutrophying Neuse River Estuary, North Carolina, USA. Marine Ecology Progress Series, 166, 17-25.

Petrone, K.C., Richards, J.S. and Grierson, P.F. (2009). Bioavailability and composition of dissolved organic carbon and nitrogen in a near coastal catchment of south-western Australia. Biogeochemistry, 92, 27-40.

Roberts, K.L., Eate, V.M., Eyre, B.D., Holland, D.P. and Cook, P.L.M. (2013). Hypoxic events stimulate nitrogen recycling in a shallow salt-wedge estuary: The Yarra River Estuary, Australia. Limnology and Oceanography, 57, 1427-1442.

Umlauf, L., and Burchard, H. (2003). A generic length-scale equation for geophysical turbulence models. Journal of Marine Research, 61, 235-265. 